\title{
The effect of work satisfaction and organizational commitment on human resources performance at the provision and protocol section regional secretariat of Karo District
}

\author{
Novia Silaen $^{1^{*}}$, David Situmorang ${ }^{2}$, Santy Ginting $^{3}$, Ketrin Simanjuntak ${ }^{4}$, Andre \\ Bastian $^{5}$ \\ 1,2,3,4,5 Fakultas Ekonomi Universitas Darma Agung
}

\begin{abstract}
This study with the title The Effect of Job Satisfaction and Organizational Commitment on Performance, which aims to determine the effect parsilally and simultaneously carried out by $t_{\text {test }}$ and $F_{\text {test }}$. From the research results determined that job satisfaction and organizational commitment have a positive

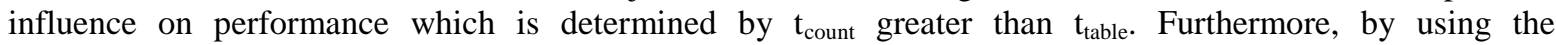

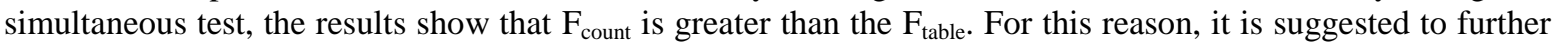
improve job satisfaction and organizational because to achieve effective commitment on performance in providing services to the community there are still many other factors that can affect, for example, training, discipline and others.
\end{abstract}

Keywords: Job Satisfaction, Organizational Commitment, Human Resources Performance

*Corresponding author: email: noviasilaen@gmail.com

\section{Pengaruh kepuasan kerja dan komitmen organisasi terhadap kinerja sumberdaya manusia pada bagian humas dan protokol sekretariat daerah Kabupaten Karo}

\author{
Novia Silaen $^{1 *}$, David Situmorang ${ }^{2}$, Santy Ginting ${ }^{3}$, Ketrin Simanjuntak ${ }^{4}$, Andre \\ Bastian $^{5}$ \\ 1,2,3,4,5 Fakultas Ekonomi Universitas Darma Agung
}

\begin{abstract}
Abstrak: Penelitian ini dilakukan pada Kantor Bagian Humas dan Protokol Sekretariat Daerah Kabupaten Karo dengan judul Pengaruh Kepuasan Kerja dan Komitmen Organisasi Terhadap Kinerja yang bertujuan untuk mengetahui pengaruh secara parsial dan simultan yang dilakukan dengan uji t dan F. Dari hasil penelitan ditentukan bahwa kepuasan kerja dan komitmen organisasi mempunyai pengaruh yang posistif terhadap kinerja yang ditentukan dengan $t_{\text {hitung }}$ lebih besar daripada $t_{\text {tabel }}$. Selanjutnya dengan menggunakan uji simultan diperoleh hasil bahwa $F_{\text {hitung }}$ lebih besar daripada $F_{\text {tabel. }}$. Untuk itu disarankan supaya lebih meningkatkan kepuasan kerja dan komitmen organisasi karena untuk mencapai kinerja yang efektif dalam memberikan pelayanan kepada masyarakat masih banyak faktor lainnya yang dapat mempengaruhi misalnya pealatihan, disiplin dan lainya.
\end{abstract}

Kata kunci: Kepuasan Kerja , Komitmen Organisasi, Kinerja Sumberdaya Manusia

*Penulis korespondensi: email: noviasilaen@gmail.com

\section{I.Pendahuluan}

\subsection{Latar Belakang}

Perkembangan sumber daya manusia untuk mencapai kepuasan dalam melakukan pekerjaan tidak telepas dari kemampuan individu untuk berbenah diri dalam mengembangkan potensi sumber daya manusia. Sumber daya manusia akan semakin berkembang dalam kaitanya dengan pencapai hasil kerja dimasa yang akan datang untuk selanjutnya seseorang dalam melakukan pekerjaan akan mengharapkan adanya perkebangan karir. Setiap individu dengan segala potensi yang ada memanfaatkan segala kemampuanya dan berusaha untuk mencapai kepuasan dengan mengandalkan kemampuan material dan non material sebagai sumbangan dalam meningkatkan kualitas pekerjaan. Kepuasan akan dicapai dalam melakukan pekerjaan dengan hasil yang memuaskan yang walaupun dengan perlakuanya banyak mengalami hambatan dan tantangan namun dengan titik kepuasan yang masksimum. Seseorang jika dihadapkan dengan berbagai macam pekerjaan tentunya nilai kepuasan kerja yang diterima mungkin berbeda dimana perbandingan antara pengorbanan dengan hasil yang diterima pada posisi tidak sebanding maka dinyatakan kurang memuaskan. Kepuasan dalam 
melakukan sebuah pekerjaan tentunya memberikan manfaat secarakeseluruhan dimana setiap individu mampu memberikan sumbangan pekerjaan untuk mencapai tujuan bersama dalam sebuah pekerjaan. Komitmen yang dibangun secara bersama-sama akan membentuk pencapaian tujuan secara global yang secara keseluruhan dipertanggungjawabkan melalui pembebanan tugas yang diselesaikan dengan optimal. Kemampuan yang terorganisir dalam jangka waktu tertentu akan merupaka komitmen organisasi yang dituangkan dalam kesepakatan bersama untuk dicapai dan dilakukan secara bersama-sama. Komitmen membangun sebuah organisasi tidak terlepas tanggung jawab setiap individu yang dituangkan dalam komitmen organisasi. Untuk mencapai kinerja yang optimal diperlukan komitmen organisasi dan kepuasan kerja yang dilaksanakan secara bersamasama untuk mencapai tujuan. Untuk mencapai kinerja dari uraian diatas maka penulis tertarik meneliti dengan judul "Pengaruh Kepuasan Kerja dan Komitmen Organisasi Terhadap Kinerja Pada Kantor Bagian Humas dan Protokol Sekretariat Daerah Kabupaten Karo".

\subsection{Batasan Masalah}

Batasan Masalah dalam penelitian ini adalah kepuasan kerja, komimen organisasi dan kinerja.

\subsection{Rumusan Masalah}

Dalam penelitian ini diperoleh rumusan masalah sebagai berikut :

1. Apakah Kepuasan Kerja Berpengaruh Terhadap Kinerja Pada Kantor Bagian Humas dan Protokol Sekretariat Daerah Kabupaten Karo?

2. Apakah Komitmen Organisasi Berpengaruh Terhadap Kinerja Pada Kantor Bagian Humas dan Protokol Sekretariat Daerah Kabupaten Karo ?

3. Apakah Kepuasan Kerja dan Komitmen Organisasi Berpengaruh serempak Terhadap Kinerja Pada Kantor Bagian Humas dan Protokol Sekretariat Daerah Kabupaten Karo ?

\section{II.Uraian Teoritis}

\subsection{Landasan Teori}

\section{Kepuasan Kerja}

Menurut Martoyo (2018:291) menyatakan, bahwa "kepuasan kerja ialah sikap seorang terhadap pelayanan mereka, sikap itu berasal dari presepsi mereka tentang pekerjaannya".

\section{Komitmen Organisasi}

Menurut Hasibuan Sayuti, (2017:90) "Pengertian komitmen organisasi adalah kelekatan emosi, identifikasi dan keterlibatan individu dengan organisasi serta keinginan untuk tetap menjadi anggota organisasi"

\section{Kinerja}

Novia (2020:1) mengatakan bahwa: "Hasil kerja yang dicapai seseorang dalam menyelesaikan tanggung jawabnya merupakan pengertian dari kinerja. Tingkat keberhasilan seseorang dalam menjalankan tugas secara keseluruhan di periode tertentu disebut juga dengan kinerja. Penyelesaian tugas dan tanggung jawab oleh sekelompok orang dalam suatu organisasi dapat juga disebut dengan kinerja."

\subsection{Kerangka Konseptual}

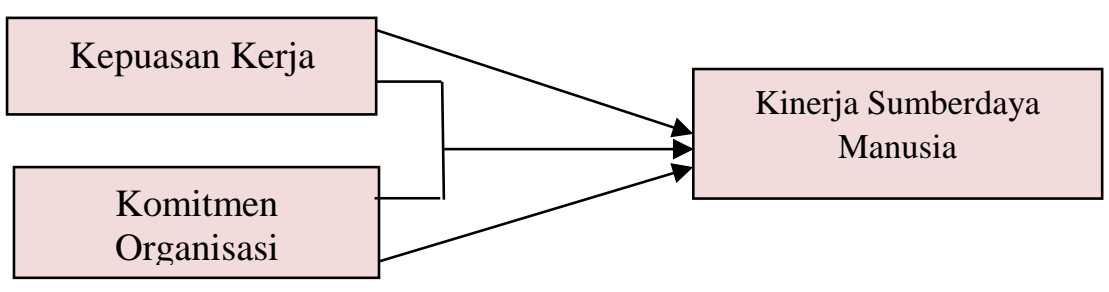

Sumber: Dikembangkan oleh peneliti, 2020

Gambar 1 Kerangka konsep 


\subsection{Hipotesis}

Hipotesis dalam penelitian ini adalah:

$\mathrm{H}_{1} \quad$ Kepuasan kerja berpengaruh terhadap kinerja pada Kantor Bagian Humas dan Protokol Sekretariat Daerah Kabupaten Karo.

$\mathrm{H}_{2}$ Komitmen organisasi berpengaruh terhadap kinerja pada Kantor Bagian Humas dan Protokol Sekretariat Daerah Kabupaten Karo.

$\mathrm{H}_{3}$ Kepuasan kerja dan komitmen organisasi berpengaruh serempak terhadap kinerja pada Kantor Bagian Humas dan Protokol Sekertariat Daerah Kabupaten Karo

\section{III.Metode Penelitian}

\subsection{Lokasi Penelitian}

Lokasi Penelitian dilakukan di pada Kantor Bagian Humas dan Protokol Sekretariat Daerah Kabupaten Karo yang beralamat di Jalan Djamin Ginting No 17 Kabanjahe.

\subsection{Populasi dan Sampel}

\section{Populasi}

Dalam penelitian ini jumlah populasi adalah semua pegawai Kantor Kantor Bagian Humas dan Protokol Sekretariat Daerah Kabupaten Karo sebanyak 123 orang karena layak dan mempunyai kesempatan yang sama untuk dijadikan populasi.

\section{Sampel}

Sampel penelitian berjumlah 41 orang pegawai Kantor Bagian Humas dan Protokol Sekretariat Daerah Kabupaten Karo dengan purposive sampling.

\section{Definisi Operasional Variabel}

Tabel 1 Definisi Operasional Variabel

\begin{tabular}{|c|c|c|c|}
\hline Variabel & Defenisi operasional & Indikator & Skala \\
\hline $\begin{array}{l}\text { Kinerja } \\
\text { (Y) }\end{array}$ & $\begin{array}{l}\text { Kinerja adalah merupakan gambaran } \\
\text { mengenai tingkat pencapaian pelaksanaan } \\
\text { suatu program kegiatan atau kebijakan } \\
\text { dalam mewujudkan sasaran, tujuan, visi dan } \\
\text { misi organisasi yang dituangkan melalui } \\
\text { perencanaan strategis suatu organisasi. } \\
\text { (Singodimedjo. 2018) }\end{array}$ & $\begin{array}{ll}\text { 1. } & \text { Produktivitas } \\
\text { 2. } & \text { Kualitas layanan } \\
\text { 3. } & \text { Responsivitas } \\
\text { 4. Responsibilitas } \\
\text { 5. Akuntabilitas }\end{array}$ & Skala Likert \\
\hline $\begin{array}{l}\text { Kepuasan kerja } \\
\text { (X1) }\end{array}$ & $\begin{array}{l}\text { Kepuasan kerja adalah perasaan pegawai } \\
\text { terhadap pekerjaannya dan terhadap } \\
\text { berbagai macam aspek dari pekerjaan } \\
\text { tersebut, sehingga kepuasan kerja sangat } \\
\text { berkaitan dengan sejauh mana pegawai puas } \\
\text { atau tidak puas dengan pekerjaannya. } \\
\text { (Sedarmayanti; 2015) }\end{array}$ & $\begin{array}{l}\text { 1. Gaji } \\
\text { 2. Promosi } \\
\text { 3. Suprvisi } \\
\text { 4. Tunjangan tambahan } \\
\text { 5. Penghargaan } \\
\text { 6. Rekan kerja }\end{array}$ & Skala Likert \\
\hline $\begin{array}{l}\text { Komitmen kerja } \\
\text { (X2) }\end{array}$ & $\begin{array}{l}\text { Komitmen organisasi adalah suatu sikap } \\
\text { dimana individu mengidentifikasikan } \\
\text { dirinya terhadap tujuan-tujuan dan harapan- } \\
\text { harapan organisasi tempat ia bekerja serta } \\
\text { berusaha menjaga keanggotaan dalam } \\
\text { organisasi untuk mewujudkan tujuan } \\
\text { organisasi tersebut. (Martoyo, 2016) }\end{array}$ & $\begin{array}{l}\text { 1. Kepercayaan } \\
\text { 2. Kemauan } \\
\text { 3. Kehendak }\end{array}$ & Skala Likert \\
\hline
\end{tabular}

Sumber: Olahan Penulis (2020) 


\section{IV.Hasil Penelitian}

\subsection{Karakteristik Responden Berdasarkan Pengalaman Kerja}

Tabel 2 Statistik Deskriptif

\begin{tabular}{|c|c|c|c|}
\hline No & Pendidikan & Jumlah (orang) & Persentase \\
\hline 1 & S2 & 6 & 14,63 \\
\hline 2 & S1 & 24 & 58,54 \\
\hline 3 & D3 & 4 & 9,76 \\
\hline 4 & SMA & 7 & 17,07 \\
\hline & Jumah & 41 & 100.00 \\
\hline
\end{tabular}

Sumber:Olahan Penulis (2020)

Karakteristik responden dapat dijelaskan bahwa Responden Berdasarkan Jenjang Pendidikan dengan jenjang pendidikan S2 sebanyak 6 orang atau setara dengan 14,63 persen, dengan jenjang pendidikan S1 sebanyak 24 orang setara dengan 58,54 persen, dengan jenjang pendidikan D3 sebanyak 4 orang setara dengan 9,67 persen dan jenjang pendidikan SMA sebanyak 7 orang yang setara dengan 17,07 persen. Dari data diatas dapat disimpulkan bahwa mayoritas pegawai didominasi dengan pendidikan S1 sebanyak 24 orang

\subsection{Uji Validitas}

Tabel 3 Uji Validitas

\begin{tabular}{clccc}
\hline Kepuasan Kerja & $(\mathbf{X 1})$ & $\mathbf{R}_{\text {hitung }}$ & $\mathbf{R}_{\text {tabel }}$ & Ket \\
\hline $\mathbf{1}$ & Gaji & 0,581 & 0,3081 & Valid \\
$\mathbf{2}$ & Promosi & 0,596 & 0,3081 & Valid \\
$\mathbf{3}$ & Supervisi & 0,712 & 0,3081 & Valid \\
$\mathbf{4}$ & Tunjangan tambahan & 0,581 & 0,3081 & Valid \\
$\mathbf{5}$ & Penghargaan & 0,596 & 0,3081 & Valid \\
$\mathbf{6}$ & Rekan kerja & 0,712 & 0,3081 & Valid \\
Komitmen Organisasi (X2) & & & \\
$\mathbf{1}$ & Kepercayaan dan penerimaan & 0,349 & 0,3081 & Valid \\
$\mathbf{2}$ & Kemauan terwujudnya kepentingan organisasi & 0,329 & 0,3081 & Valid \\
$\mathbf{3}$ & Kehendak mempertahankan keanggotaan & 0,472 & 0,3081 & Valid \\
Indikator Kinerja (Y) & & & \\
$\mathbf{1}$ & Produktivitas & 0,564 & 0,3081 & Valid \\
$\mathbf{2}$ & Kualitas layanan & 0,581 & 0,3081 & Valid \\
$\mathbf{3}$ & Responsivitas & 0,596 & 0,3081 & Valid \\
$\mathbf{4}$ & Responsibilitas & 0,712 & 0,3081 & Valid \\
$\mathbf{5}$ & Akuntabilitas & 0,349 & 0,3081 & Valid \\
\hline
\end{tabular}

Sumber:Olahan Penulis(2020)

Adapun kriteria yang digunakan dalam menentukan valid tidaknya pernyataan digunakan derajat kebebasan $(\mathrm{df})=\mathrm{n}-\mathrm{k}=41-2=39$. Dan $\mathrm{r}_{\text {tabel }}=0,3081$. Jika $\mathrm{r}_{\text {hitung }}$ lebih besar dari $\mathrm{r}_{\text {tabel }}$ maka butir pernyataan dikatakan valid.

\subsection{Uji Reliabilitas}

Tabel 4 Uji Reliabilitas

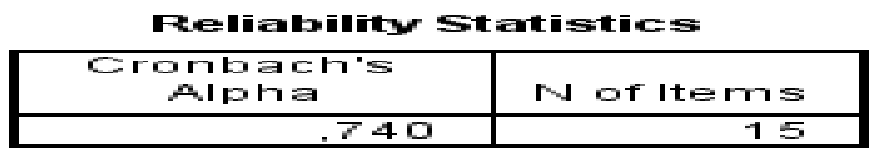

Sumber: Diolah dari data primer, 2020 
Berdasarkan hasil pengujian yang dilakukan pada variabel loyalitas, kinerja dan kepuasan kerja seluruhnya menunjukkan nilai Cronbach Alpha berada 0,740 lebih besar dari 0,60 maka dapat disimpulkan bahwa semua variabel telah reliabel dan dapat diandalkan.

\subsection{Uji Asumsi Klasik}

\section{Uji Normalitas}

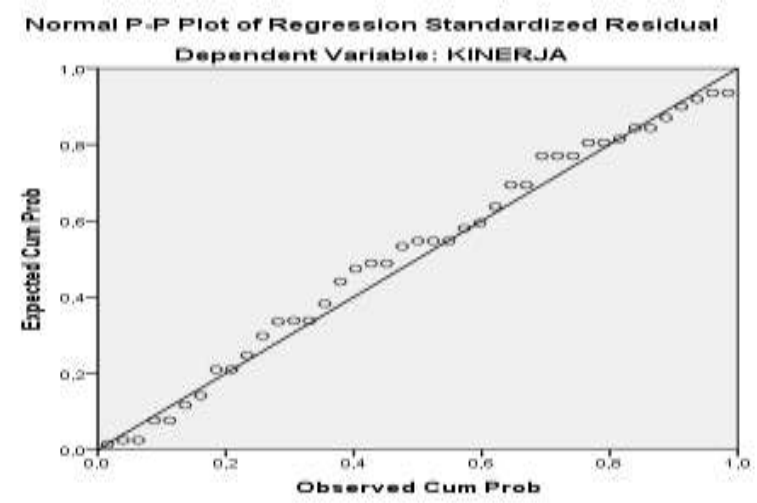

Sumber: Olahan Penulis (2020)

Gambar 2 Grafik Uji Normalitas P-Plot

Grafik normal probability plot menunjukkan bahwa data atau titik- titik menyebar di sekitar garis diagonal yang mengikuti arah garis diagonal, maka model regresi memenuhi asumsi normalitas.

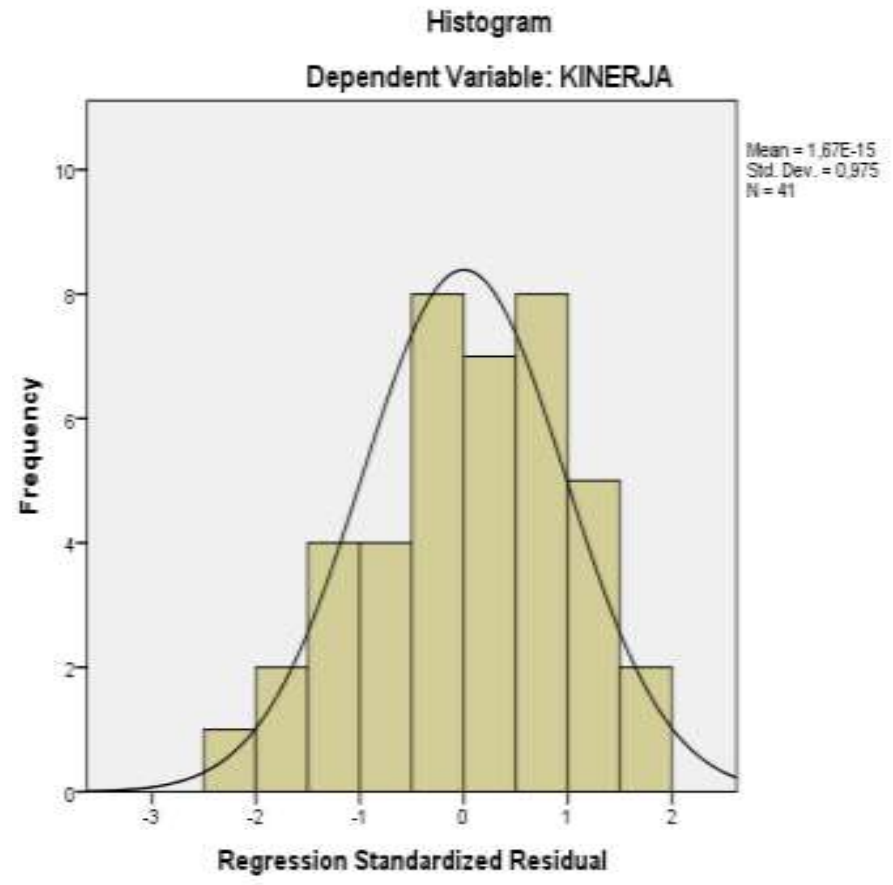

Sumber: Olahan Penulis (2020)

Gambar 3 Histogram Uji Normalitas

Dari grafik histogram diatas dapat disimpulkan bahwa grafik histogram telah memenuhi normalitas dimana bentuk kurva pada dua sisi kiri dan kanan adalah simetris dengan kedua bidang yang sama. Bentuk dengan dua sisi tersebut menunjukkan bahwa asumsi klasik dengan menggunakan histogram telah dipenuhi. 


\section{Uji Multikolinearitas}

Tabel 5 Uji Multikolinearitas

\begin{tabular}{|c|c|c|c|c|c|c|c|c|c|c|c|}
\hline \multirow[b]{2}{*}{ Mode } & & \multicolumn{2}{|c|}{ Unstandardiced Coefficients } & \multirow{2}{*}{$\begin{array}{c}\begin{array}{c}\text { Standardized } \\
\text { Coeficients }\end{array} \\
\text { Beta }\end{array}$} & \multirow[b]{2}{*}{$t$} & \multirow[b]{2}{*}{ Sig. } & \multicolumn{3}{|c|}{ Correlations } & \multicolumn{2}{|c|}{ Collinearity Statistics } \\
\hline & & B & Std. Error & & & & Zero-order & Partial & Part & Tolerance & VF \\
\hline \multirow[t]{3}{*}{1} & (Constant) & 1,849 & 1,055 & & 1,753 &, 088 & & & & & \\
\hline & KEPUASAN KERUA & .587 &, 045 & .847 & 13,119 &, 000 & 911 & .905 &, 794 & 880 & 1,136 \\
\hline & KOMTNEN ORGANSSASI & 251 & .087 & 187 & 2,892 & .006 & 479 & .425 & .175 & 880 & 1.136 \\
\hline
\end{tabular}

a. Dependert Variable: KINERJA

Sumber: Diolah dari data primer, 2020

Tabel 4.5 diatas terlihat bahwa nilai VIF kurang dari 10 dan nilai toleransi yang lebih dari 0,1 , berarti bahwa tidak terdapat multikolinieritas/kolerasi antar variabel bebas.

\section{Uji Heterokedastisitas}

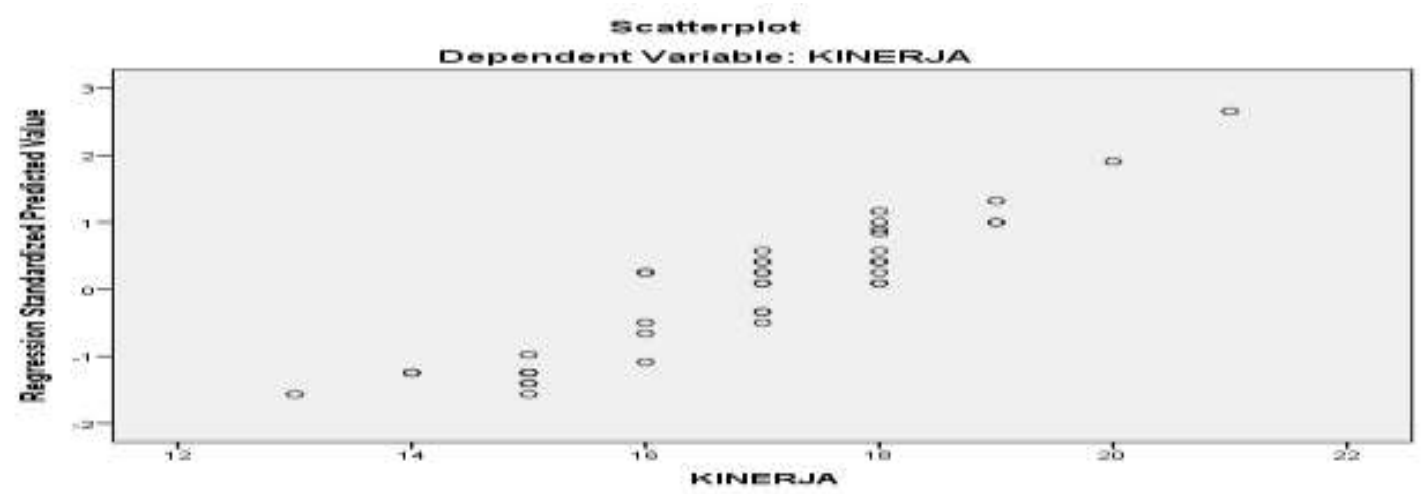

Sumber: Olahan Penulis (2020)

Gambar 4 Scatterplot Uji Heterokedastisitas

Hasil pengujian heteroskedastisitas menunjukkan bahwa titik-titik yang tidak membentuk pola tertentu atau tidak ada pola yang jelas serta titik-titik menyebar di atas dan dibawah angka 0 (nol) pada sumbu Y, maka tidak terjadi heteroskedastisitas.

\section{Regresi Linier Berganda}

Tabel 6 Regresi Linier Berganda

Coefficients ${ }^{\mathrm{a}}$

\begin{tabular}{|c|c|c|c|c|c|c|c|c|c|c|c|}
\hline \multirow[b]{2}{*}{ Model } & & \multicolumn{2}{|c|}{ Unstandardiced Coefficients } & \multirow{2}{*}{$\begin{array}{c}\text { Standardized } \\
\text { Coeficients } \\
\text { Beta }\end{array}$} & \multirow[b]{2}{*}{$t$} & \multirow[b]{2}{*}{ Sig. } & \multicolumn{3}{|c|}{ Correlations } & \multicolumn{2}{|c|}{ Collinearity Statistics } \\
\hline & & B & Std. Error & & & & Zero-order & Partial & Part & Tolerance & VF \\
\hline 1 & (Constant) & 1,849 & 1,055 & & 1,753 &, 088 & & & & & \\
\hline & KEPUASAN KERUA & 587 &, 045 & .847 & 13,119 &, 000 & 911 &, 905 & 794 & 880 & 1,136 \\
\hline & KOMTMEN ORGANSASI & 251 &, 087 & 187 & 2,892 &, 006 & 479 & .425 & .175 & 880 & 1,136 \\
\hline
\end{tabular}

a. Dependert Variable: KINERJA

Sumber: Olahan Penulis (2020)

Dari hasil tersebut diatas, apabila ditulis dalam bentuk persamaan regresinya adalah sebagai berikut : $\mathrm{Y}=1,849+0,587 \mathrm{X}_{1}+0,251 \mathrm{X}_{2}$

Keterangan: $\quad \mathrm{Y}=$ Kinerja, $\mathrm{X}_{1}=$ Kepuasan Kerja, dan $\mathrm{X}_{2}=$ Komitmen Organisasi

Persamaan analisis regresi linear berganda ini dapat diartikan sebagai berikut: 
1. Nilai konstanta 1,849 artinya kinerja mengalami kenaikan sebesar 1,849 jika kepuasan dan komitmen organisasi tidak dimasukkan dalam persamaan.

2. Nilai koefisien regresi kepuasan kerja $\left(\mathrm{X}_{1}\right)$ sebesar 0,587 artinya kinerja akan naik diakibatkan oleh kepusan kerja sebesar 58,7.

3. Nilai koefisien regresi kepuasan kerja $\left(\mathrm{X}_{2}\right)$ sebesar 0,251 artinya kinerja akan meningkat akibat kenaikan kepuasan kerja sebesar 25,1.

\section{Uji t}

Tabel 7 Uji t

Coefficients $^{\mathrm{a}}$

\begin{tabular}{|c|c|c|c|c|c|c|c|c|c|c|c|}
\hline \multirow[b]{2}{*}{ Model } & & \multicolumn{2}{|c|}{ Unstandardiced Coefficients } & \multirow{2}{*}{$\begin{array}{c}\text { Standardized } \\
\text { Coeficients }\end{array}$} & \multirow[b]{2}{*}{$t$} & \multirow[b]{2}{*}{ Sig. } & \multicolumn{3}{|c|}{ Correlations } & \multicolumn{2}{|c|}{ Collinearity Statistics } \\
\hline & & $\mathrm{B}$ & Std. Error & & & & Zero-order & Partial & Part & Tolerance & VF \\
\hline 1 & (Constant) & 1,849 & 1,055 & & 1,753 &, 088 & & & & & \\
\hline & KEPUASAN KERJA & .587 & 045 & .847 & 13,119 &, 000 & 911 &, 905 &, 794 &, 880 & 1,136 \\
\hline & KOMITUEN ORGANSASI & 251 &, 087 & .187 & 2,892 & 006 & 479 & 425 & 175 &, 880 & 1,136 \\
\hline
\end{tabular}

a. Dependert Variable: KINERIA

Sumber: Olahan Penulis (2020)

a. Variabel Kepuasan Kerja

Jika $t_{\text {hitung }}>t_{\text {tabel }}$ : Kepuasan kerja berpengaruh positif terhadap kinerja. Hasil SPSS menujukkan nilai $\mathrm{X}_{1}$ (kepuasan kerja) diperoleh nilai $\mathrm{t}_{\text {hitung }}=13,119$ dengan nilai $\mathrm{t}_{\text {tabel }}=2,03369$ maka keputusan menerima $\mathrm{H}_{\mathrm{a}}$ dan menolak $\mathrm{H}_{0}$ karena $\mathrm{t}_{\text {hitung }}$ lebih besar dari $\mathrm{t}_{\text {tabel. }}$.

b. Variabel Komitmen Organisasi

Jika $t_{\text {hitung }}>t_{\text {tabel }}$ : Kinerja berpengaruh positif signifikan terhadap komitmen organisasi. Hasil pengujian menunjukkan nilai variabel $\mathrm{X}_{2}$ (komitmen organisasi) diperoleh nilai $t_{\text {hitung }}=2,892$ dengan nilai $\mathrm{t}_{\text {tabel }}=2,02269$ maka menerima $\mathrm{H}_{\mathrm{a}}$ dan menolak $\mathrm{H}_{0}$ karena nilai $\mathrm{t}_{\text {hitung }}$ lebih besar dari $\mathrm{t}_{\text {tabel. }}$

6. Uji F

Tabel 8 Uji F

ANOVA $^{a}$

\begin{tabular}{|ll|r|r|r|r|r|}
\hline Model & & $\begin{array}{c}\text { Sum of } \\
\text { Squares }\end{array}$ & df & Mean Square & F & Sig. \\
\hline 1 & Regression & 98,456 & 2 & 49,228 & 117,398 &, $000^{\mathrm{b}}$ \\
& Residual & 15,934 & 38 &, 419 & & \\
& Total & 114,390 & 40 & & & \\
\hline
\end{tabular}

a. Dependent Variable: KINERJA

b. Predictors: (Constant), KOMITMEN ORGANISASI, KEPUASAN KERJA

Sumber: Olahan Penulis (2020)

Pengambilan keputusan dengan menggunakan uji $\mathrm{F}$ sebagai berikut : jika $\mathrm{F}_{\text {hitung }}>\mathrm{F}_{\text {tabel }}$ : berarti ada pengaruh yang signifikan antara kepuasan kerja dan komitmen organisasi secara bersama-sama terhadap kinerja. Hasil perhitungan statistik menunjukkan nilai $\mathrm{F}_{\text {hitung }}=117,398$ dengan nilai $\mathrm{F}_{\text {tabel }}=$ 3,24 . Hal ini berarti bahwa secara bersama-sama kepuasan kerja dan komitmen organisasi mempunyai pengaruh terhadap kepuasan kerja atau $\mathrm{H}_{\mathrm{a}}$ diterima dan $\mathrm{H}_{0}$ ditolak. 


\section{Koefisien Determinasi}

Tabel 9 Koefisien Determinasi

\begin{tabular}{|c|c|c|c|c|c|c|c|c|c|c|}
\hline \multirow[b]{3}{*}{ Model } & \multirow[b]{3}{*}{$\mathrm{R}$} & \multirow[b]{3}{*}{ R Square } & \multicolumn{7}{|c|}{ Model Summary ${ }^{b}$} & \multirow[b]{3}{*}{$\begin{array}{l}\text { Durbin- } \\
\text { Watson }\end{array}$} \\
\hline & & & & & \multicolumn{5}{|c|}{ Change Statistics } & \\
\hline & & & $\begin{array}{l}\text { Adjusted R } \\
\text { Square }\end{array}$ & $\begin{array}{l}\text { Std. Error of } \\
\text { the Estimate }\end{array}$ & $\begin{array}{c}\text { R Square } \\
\text { Change }\end{array}$ & F Change & df1 & df2 & $\begin{array}{l}\text { Sig. F } \\
\text { Change }\end{array}$ & \\
\hline 1 & $928^{\mathrm{a}}$ & 861 & 853 & 648 & .861 & 117,398 & 2 & 38 & ,000 & 1,929 \\
\hline
\end{tabular}

a. Predictors: (Constant), KOMITMEN ORGANISASI, KEPUASAN KERJA

b. Dependent Variable: KINERJA

Sumber: Olahan Penulis (2020)

Dari uraian tabel diatas diketahui bahwa variasi dari variabel diketahui bahwa koefisien determinasi (adjusted $\mathrm{R}^{2}$ ) yang diperoleh sebesar 0,861. Hal ini berarti 86,1\%, kinerja dapat dijelaskan oleh variabel kepuasan kerja dan komitmen organisasi sedangkan sisanya yaitu 13,9\% (100-86,1) dipengaruhi oleh variabel-variabel lainnya diluar penelitian ini, misalnya disiplin kerja, pelatihan dll.

\section{Pembahasan Hasil Penelitian}

\subsection{Pengaruh Kepuasan Kerja Terhadap Kinerja}

Penelitian dilakukan oleh Sugit tahun 2018, Rafig tahun 2011, Agustinus tahun 2011 menujukkan bahwa kepuasan kerja mempunyai pengaruh yang positif dan signifikan terhadap kinerja sedangkan dengan penelitian ini menunjukkan bahwa kepuasan kerja berpengaruh terhadap kinerja yang berarti menerima $\mathrm{H}_{\mathrm{a}}$ dan menolak $\mathrm{H}_{0}$ yang ditunjukkan oleh $\mathrm{t}_{\text {hitung }}$ lebih kecil daripada $\mathrm{t}_{\text {tabel. }}$.

\subsection{Pengaruh Komitmen Organisasi Terhadap Kinerja}

Penelitian dilakukan oleh Sugit tahun 2018, Rafig tahun 2011, Agustinus tahun 2011 menujukkan bahwa komitmen organisasi mempunyai pengaruh yang positif dan signifikan terhadap kinerja sedangkan dengan penelitian ini menunjukkan bahwa pengaruh yang positif yang berarti menerima $\mathrm{H}_{\mathrm{a}}$ dan menolak $\mathrm{H}_{0}$ yang ditunjukkan oleh $\mathrm{t}_{\text {hitung }}$ lebih besar daripada $\mathrm{t}_{\text {tabel }}$

\subsection{Pengaruh Kepuasan Kerja dan Komitmen Organisai Terhadap Kinerja}

Penelitian dilakukan oleh Sugit tahun 2018, Rafig tahun 2011, Agustinus tahun 2011 menujukkan bahwa kepuasan kerja dan komitmen organisasi mempunyai pengaruh yang positif dan signifikan terhadap kinerja sedangkan dengan penelitian ini menunjukkan bahwa pengaruh yang positif yang berarti menerima $\mathrm{H}_{\mathrm{a}}$ dan menolak $\mathrm{H}_{0}$ yang ditunjukkan oleh $\mathrm{F}_{\text {hitung }}$ lebih besar dari pada $\mathrm{F}_{\text {tabel. }}$.

\section{Kesimpulan dan Saran}

\subsection{Kesimpulan}

Berdasarkan hasil penelitian dan kajian yang telah diuraikan sebelumnya, maka dapat disimpulkan menjadi beberapa hal sebagai berikut :

1. Variabel kepuasan kerja mempunyai pengaruh yang positif dan signifikan Dengan menggunakan hubungan secara individu bahwa kepuasan kerja mempunyai pengaruh yang positif terhadap kinerja yang ditunjukkan oleh $t_{\text {hitung }}$ lebih besar daripada $t_{\text {tabel }}$

2. Dengan menggunakan hubungan individu bahwa komitmen organisasi berpengaruh terhadap kinerja yang ditunjukkan $t_{\text {hitung }}$ lebih besar daripada $t_{\text {tabel. }}$

3. Dengan menggunakan bersama-sama bahwa kepuasan kerja dan komitmen organisasi mempunyai pengaruh yang positif terhadap kinerja yang ditunjukkan oleh $\mathrm{F}_{\text {hitung }}$ lebih besar daripada $\mathrm{F}_{\text {tabel. }}$. 


\subsection{Keterbatasan Penelitian}

Penelitian ini telah diusahakan dan dilaksanakan sesuai prosedur ilmiah, namun demikian masih memiliki keterbatasan yaitu :

1. Keterbatasan dalam penelitian ini hanya kepuasan kerja, komitmen organisasi dan kinerja yang dilakukan pada Kantor Kantor Bagian Humas dan Protokol Sekretariat Daerah Kabupaten Karo

2. Adanya keterbatasan penelitian dengan menggunakan sampel sebanyak 41 orang yang dilakukan dengan menggunakan kuesioner yang dimungkinkan mempunyai kelemahan dalam konsistensi jawaban jika digunakan pada orang yang berbeda dan kondisi yang berbeda.

\subsection{Saran}

Berdasarkan kesimpulan yang diuraikan di atas, maka disarankan :

1. Dengan menggunakan hubungan yang dibentuk pada kepuasan kerja dan komitmen organisasi berpengaruh secara positif maka disarankan untuk mempertahankan dan meningkatkan untuk mencapai kinerja yang optimal dalam memberikan pelayanan kepada masyarakat.

2. Dalam penelitian ini membahas kepuasan kerja dan komitmen organisasi sementara dalam mencapai kinerja yang baik masih banyak hal lainnya yang harus dilakukan seperti pelatihan, lingkungan kerja yang merupakan salah satu faktor lainnya yang harus dipertimbangkan.

\section{Kepustakaan}

Afandi, P. 2018. Manajemen Sumber Daya Manusia (Teori, Konsep dan Indikator). Riau: Zanafa Publishing.

Arikunto, S. 2018. Prosedur Penelitian Suatu Pendekatan Praktis. Jakarta: Rineka Cipta.

Ghozali, Imam. 2015. Model Persamaan Struktural Konsep Dan Aplikasi Dengan Program Amos 19.0. Semarang: Badan Penerbit Undip

Gomes, F. Cardoso 2015, Manajemen Sumber Daya Manusia. Edisi 2. Yogyakarta. ANDI

Hariandja, Marihot Tua Efendi. 2016. Manajemen Sumber Daya Manusia. Edisi Pertama, Jakarta: Grasindo.

Hasibuan Sayuti, 2017. Manajemen Sumber Daya Manusia, Muhammadiyah university Press, Surakarta.

Henry Simamora. 2016. Manajemen Sumber Daya Manusia. Yogyakarta: BP STIE YKPN

Manurung, Jonni. 2005. Ekonometrika: Teknik Pemodelan Dasar dan Lanjutan. Cetakan Pertama, Jakarta: PT Alex Media Komputindo.

Martoyo. 20018. Manajemen Sumber Daya Manusia. Bandung: Alfabeta.

Martoyo, 2016. Manajemen Sumber Daya Manusia. Edisi Kelima, Cetakan Pertama, Yogyakarta: BPFEUGM.

Nawawi, Hadadari, H 2017 Manajemen Sumber Daya Manusia. Edisi 1, Cetakan Ke 4. Jogjakarta, Gadjah Mada Press

Nursalam. 2018. Konsep dan Penerapan Metodologi Penelitian. Jakarta: Salemba Medika Indonesia.

Payaman Simanjuntak. 2015. Manajemen dan Evaluasi Kinerja. Penerbit Lembaga Fakultas Ekonomi Universitas Indonesia, Jakarta

Sedarmayanti. 2015. Sumber Daya Manusia dan Produktivitas Kerja, Jakarta: Mandar Maju

Silaen, Novia R., et al. Kinerja Karyawan. Widina Bhakti Persada Bandung, 2021. https://repository.penerbitwidina.com/publications/344479/kinerja-karyawan\#cite 
Jurnal Global Manajemen Program Studi S1 Manajemen FE-UDA, Volume 10 Nomor 1, Juni 2021 ISSN: 2088-8325, E-ISSN: 2715-6001

Singodimedjo. 2018. Manajemen Sumber Daya Manusia. Jakarta: Ghalia Indonesia Siregar, Sofian. 2016. Metode Penelitian Kuantitatif. Jakarta: Kencana Prenada Media Group Sopiah. 2016. Perilaku Organisasional. Edisi Pertama, Yogyakarta: Andi.

Sunyoto, Danang. 2017. Metode dan Instrumen Penelitian Ekonomi dan Bisnis. Cetakan Pertama, Yogyakarta: Caps.

Sugiyono. 2016. Metode Penelitian Pendidikan. Bandung: Alfabeta. 